\title{
Can Education Resolve Nursing Shortage in China?
}

\author{
By Junhong Zhu* \\ Sheila Rodgers ${ }^{\dagger}$ \\ Kath M. Meliat
}

The paper aims to understand how the Chinese nursing education and recruitment policy impacts nurses to leave nursing practice. There is a lack of feasible strategies to maintain a sustainable effective nursing workforce with an increasing trend of nurses' leaving clinical care. In its efforts to resolve the nursing shortage, the Chinese government currently emphasizes expanding nursing education while controlling staffing ratios. This qualitative research design was based on the framework of symbolic interactionism. The in-depth interviews with 19 nurses who have left the nursing practice were theoretically sampled from one provincial capital city in China. The core category "Mismatched Expectations: Individual vs. Organization" emerged from five subcategories, which illustrates how the mismatched individual and organizational expectations of nursing were created through nurses educational and employment processes within the Chinese health care system. When the individual and organizational expectations of nursing are highly mismatched, there is a risk that highly educated nurses will leave nursing practice. Students should be enabled to have realistic expectations of nursing, and new graduates need sufficient supports to adapt to the health care environment without losing their vision of nursing for future.

Key words: China, Nursing education, Nursing shortage, Recruitment.

\section{Background}

A high rate of nursing turnover has incurred great educational and human resources wastage (Kotecha 2002, Lavoie-Tremblay et al. 2008, Pellico et al. 2009). It is presumed that the educators and hospital managers have a common awareness that retention of staff is an important issue and that they wish to manage turnover effectively (Hayes et al. 2006). There is no sound evidence to prove whether the educators and hospital managers in developing countries have a similar awareness or the motivation to retain qualified nurses (Dovlo 2005, Gill 2011, Xu 2003), which may be a particular concern in China. The Chinese government uses expansion of nursing education in order to solve the nursing shortage, but has shifted from government supported free education to students' self-funded education as the consequence of the national higher education reforms (MHPRC 2005). The enrolment of students in higher levels of nursing education shows an increasing trend from 2001 to 2014 (Table 1 and

\footnotetext{
*Postdoctoral Associate, Arthur Labatt Family School of Nursing, University of Western London, Ontario, Canada.

${ }^{\dagger}$ Head of Nursing Studies, School of Health in Social Science, University of Edinburgh, UK.

${ }^{*}$ Professor, Nursing Studies, School of Health in Social Science, University of Edinburgh, UK.
} 
Table 2). The government declared that $51.3 \%$ of clinical nurses already have an associate degree or a higher degree and expected those ratios would continue increasing to $60 \%$ by 2015 (MHPRC 2011). However, an increasing loss of Chinese nurses after graduation has been mentioned (Anand et al. 2008, Fang 2007, Xu 2003).

Table 1. Multilevel Nursing Education and Nursing Workforce in China

\begin{tabular}{|l|c|c|c|c|}
\hline Types of programme & $\begin{array}{c}\text { Age of } \\
\text { entry }\end{array}$ & $\begin{array}{c}\text { Years of } \\
\text { study }\end{array}$ & $\begin{array}{c}\text { Percentage of } \\
\text { the workforce in } \\
\mathbf{2 0 0 5}\end{array}$ & $\begin{array}{c}\text { Percentage of all } \\
\text { the workforce in } \\
\mathbf{2 0 1 3}\end{array}$ \\
\hline Diploma & $15-16$ & 3 & $85-95 \%$ & $51 \%$ \\
\hline Associate degree & 18 & 3 & $4-8 \%$ & $38 \%$ \\
\hline Bachelor degree & 18 & $4-5$ & $6 \%$ & $11 \%$ \\
\hline $\begin{array}{l}\text { Postgraduate education } \\
\text { (Master and Doctorate Degree) }\end{array}$ & $<35$ & 3 & $\mathrm{n} / \mathrm{a}$ & $\mathrm{n} / \mathrm{a}$ \\
\hline
\end{tabular}

Source: MHPRC 2005, ICN 2013.

Table 2. Chinese Nursing School Recruitment

\begin{tabular}{|l|c|c|c|c|c|c|c|c|}
\hline \multirow{2}{*}{$\begin{array}{l}\text { Types of } \\
\text { programme }\end{array}$} & \multicolumn{2}{|c|}{$\mathbf{2 0 0 1}$} & \multicolumn{2}{c|}{$\mathbf{2 0 0 5}$} & \multicolumn{2}{c|}{$\mathbf{2 0 1 0}$} & \multicolumn{2}{|c|}{$\mathbf{2 0 1 3}$} \\
\cline { 2 - 9 } & Number & $\%$ & Number & $\%$ & Number & $\%$ & Number & $\%$ \\
\hline Diploma & 75,000 & $71 \%$ & 88,000 & $62 \%$ & 82,200 & $50 \%$ & 488,779 & $71 \%$ \\
\hline $\begin{array}{l}\text { Associate } \\
\text { degree }\end{array}$ & 25,000 & $23 \%$ & 38,200 & $27 \%$ & 49,200 & $30 \%$ & 161,038 & $23 \%$ \\
\hline $\begin{array}{l}\text { Bachelor } \\
\text { degree }\end{array}$ & 6,500 & $6 \%$ & 15,100 & $11 \%$ & 32,000 & $20 \%$ & 42,878 & $6 \%$ \\
\hline Total & $<\mathbf{1 0 6 , 5 0 0}$ & $\mathbf{1 0 0 \%}$ & $\mathbf{1 4 1 , 3 0 0}$ & $\mathbf{1 0 0 \%}$ & $\mathbf{1 6 4 , 3 0 0}$ & $\mathbf{1 0 0 \%}$ & $\mathbf{6 9 2 , 6 9 5}$ & $\mathbf{1 0 0 \%}$ \\
\hline
\end{tabular}

Source: MHPRC 2005, ICN 2013.

In 1978, the Chinese government established dingbian as a staffing legislation in the national health care system (MHPRC 1978). The standards of dingbian focus on the numbers of all types of hospital staff per bed based on the size of the hospitals and the ratio of doctors to nurses is stipulated (Table 3 ). It is different from the current international nursing staffing policy in most western countries, which focuses on the number of patients per nurse based on the work-unit (Aiken and Cheung 2008, Conway et al. 2008, Rafferty et al. 2007). From 1979, the Chinese health-care system gradually transferred from a planned to a market economy (Hsiao 2008). Since then, the State subsidy has been cut annually, from $30 \%$ to less than $7 \%$ of total hospital expenditure (Blumenthal and Hsiao 2005). Due to a lack of valid monitoring mechanisms in Chinese hospitals ( $\mathrm{Ma}$ et al. 2008, Wu 1997), the hospital managers are reluctant to admit that nurses are important to the quality and safety of care based on a profit motive driver (Hsiao 2008, Zhu et al. 2014). Consequently, controlling the ratio of nursing staff became the main strategy used by the hospital managers to achieve cost efficiency. There is a lack of feasible strategies to retain and attract nurses back to nursing in China (Fang 2007, Zhu 2010, Zhu et al.2015). 
Table 3. The Discrepancy between Dingbian and Actual Staffing in Chinese Health System

\begin{tabular}{|c|c|c|c|c|c|c|}
\hline \multirow{2}{*}{$\begin{array}{l}\text { The ratio of } \\
\text { staffing } \\
\text { (numbers of } \\
\text { all health } \\
\text { staff/ beds) }\end{array}$} & \multicolumn{3}{|c|}{$\begin{array}{c}\text { Hospital size } \\
\text { (number of beds) }\end{array}$} & \multirow{2}{*}{$\begin{array}{c}\text { Average } \\
\text { ratio of } \\
\text { nurses/beds }\end{array}$} & \multirow{2}{*}{$\begin{array}{l}\text { Ratio of } \\
\text { doctors/ } \\
\text { nurses }\end{array}$} & \multirow{2}{*}{ Sources } \\
\hline & $<300$ & $300-500$ & $>500$ & & & \\
\hline Dingbian & \begin{tabular}{|l}
$1.30-$ \\
$1.40: 1$
\end{tabular} & $\begin{array}{c}1.40- \\
1.50: 1 \\
\end{array}$ & \begin{tabular}{|l|}
$1.60-$ \\
$1.70: 1$ \\
\end{tabular} & $0.4: 1$ & $1: 1.5-2.0$ & MHPRC 1978 \\
\hline $\begin{array}{l}\text { Actual ratio } \\
\text { of staffing } \\
\text { (Zhejiang } \\
\text { Province) } \\
\end{array}$ & $1.32: 1$ & $1.33: 1$ & $1.53: 1$ & $<0.4: 1$ & $>1: 1.5$ & $\begin{array}{l}\text { Liang et al. } \\
2007\end{array}$ \\
\hline $\begin{array}{l}\text { Actual ratio } \\
\text { of staffing } \\
\text { (Nationwide) }\end{array}$ & $\mathrm{n} / \mathrm{a}$ & $\mathrm{n} / \mathrm{a}$ & $\mathrm{n} / \mathrm{a}$ & $0.33: 1$ & $\begin{array}{l}1: 2.28(1952) \\
1: 1.09(2001) \\
1: 0.68(2003) \\
1: 1.16(2011) \\
1: 1.03(2014)\end{array}$ & $\begin{array}{c}\text { MHPRC } 2005 \\
\text { MHPRC } 2011 \\
\text { WHO } 2014\end{array}$ \\
\hline
\end{tabular}

\section{The Study}

Aim

The study aims to explore how nursing education and employment policy impacts on Chinese nurses' career decision making. The research questions focus on: how do the nurses who leave nursing describe their experiences through the processes of nursing education and recruitment, and are education issues part of the reason for their leaving nursing practice in China?

Design

A qualitative study design was based on symbolic interactionism (Blumer 1969, Glaser and Strauss 1967). The key premises of symbolic interactionism provide an interpretative view of sociology which emphasizes understanding the actions of participants in their active experience and the ways in which their actions arise from and reflect back their experience (Blumer 1969). The theoretical framework of symbolic interactionism supports in-depth interviews with nurses who left clinical care as the best way to collect data (Zhu 2012).

\section{Participants and Research Setting}

The research site is located in one provincial capital city in the east of China. The interview participants include 19 nurses who have worked in all areas of clinical care apart from mental health care, and have left their nursing practice in the last 5 years. The rationale of setting the leaving period at a maximum of 5 years allows participants enough time and space to make sense of their actions as an outsider looking back from their current position at their nursing career decision-making process when the consequences of their departure have become apparent. 


\section{Ethical Considerations}

Ethical approval has been granted from the Research Ethics Committee of Edinburgh University. We did not use organizational gatekeepers to identify the potential participants from the Chinese Health authority, since we believe that nurses who left their nursing practice are professionals, have the knowledge and ability to understand the nature of the study and can participant the study based on informed consent without organizational approvals.

\section{Data Collection}

Each in-depth formal interview lasted 2 to 3 hours on average. The selection criteria for the next interviewee always followed the previous interview analysis in the field, which was guided by the principle of theoretical sampling (Glaser and Strauss 1967, Silverman 2010). As the data analysis progressed, the category "entering the ideal workplace" indicated that the Grade three hospitals were initially regarded by participants as the ideal workplace, where the most well educated and best qualified nurses were recruited (Zhu 2012). A decision was made to narrow down and focus on the former nurses from Grade three hospitals only in order to address the reality fully and effectively (Zhu 2012).

\section{Data Analysis}

The process of theoretical sampling and the constant comparative analysis was followed as outlined by Glaser and Strauss (1967). We were concerned that the accuracy of the study should be achieved by basing it on culture sensitivity. Therefore, all interviews were recoded and transcribed verbatim and kept as the most original data for the researchers to check the accuracy of interpretation and translation during different stages of analysis and presentation by constantly comparing one piece of data with another, back and forward between two languages. Glaser and Strauss (1967) emphasise that a comprehensive literature review should be avoided by following a grounded approach before the data analysis. Therefore we only start to integrate literature review into analysis as second data when the core categories emerged clearly from primary in-depth interview data, which avoids contaminating participants' accounts due to the preconceptions from reading the literature.

\section{Findings}

The core category "Mismatched Expectations: Individual vs. Organization" emerged from the following five conceptualized subcategories (Table 4). These conceptualized categories articulated how the nursing education and employment policy impacts on Chinese nurses' career decision making. 
Table 4. Summary of the Conceptualized Categories

\begin{tabular}{|c|c|c|}
\hline Core category & Subcategories & Properties \\
\hline \multirow{5}{*}{$\begin{array}{l}\text { Mismatched } \\
\text { Expectations: } \\
\text { Individual Vs. } \\
\text { Organizational }\end{array}$} & $\begin{array}{l}\text { Entering nursing with } \\
\text { collective expectations }\end{array}$ & $\begin{array}{l}\text { - Influence of parents. } \\
\text { - Concern for health care for } \\
\text { family. } \\
\text { - Pursuing social mobility by } \\
\text { working in the city. } \\
\text { - Looking for a springboard. } \\
\text { - Advising the potential nursing } \\
\text { students. }\end{array}$ \\
\hline & $\begin{array}{l}\text { Restricting realistic } \\
\text { expectations of nursing } \\
\text { in education }\end{array}$ & $\begin{array}{l}\text { - Creating unrealistic expectations } \\
\text { from enrolment. } \\
\text { - Effects in nursing education. } \\
\text { - Clinical supervisors effects in } \\
\text { work placement. }\end{array}$ \\
\hline & $\begin{array}{c}\text { Choosing the ideal } \\
\text { workplace }\end{array}$ & $\begin{array}{l}\text { - Getting priority to choose ideal } \\
\text { workplace. } \\
\text { - Selecting by the hospitals. }\end{array}$ \\
\hline & $\begin{array}{l}\text { Commitment to the } \\
\text { organization }\end{array}$ & $\begin{array}{l}\text { - Accessing health care for } \\
\text { family. } \\
\text { - Gaining a stable job as woman. } \\
\text { - Attaching to the hospital within } \\
\text { dingbian. } \\
\text { - Expecting doing a good job. }\end{array}$ \\
\hline & $\begin{array}{l}\text { Struggling with a } \\
\text { professional identity }\end{array}$ & $\begin{array}{l}\text { - Gaps between theory and } \\
\text { practice. } \\
\text { - Lack of clear role boundaries } \\
\text { and skill-mix team work. } \\
\text { - Intensifying individual nurses' } \\
\text { workload. } \\
\text { - Working stress and the } \\
\text { wellbeing of nurses. } \\
\text { - Losing confidence in the safety } \\
\text { and quality of health care. }\end{array}$ \\
\hline
\end{tabular}

Entering Nursing with Collective Expectations

The participants entered different levels of nursing studies under a variety of tuition fee arrangements. It was surprising that nearly all of the participants mentioned that they did not have a clear idea of nursing before they entered nursing school. The predominant reasons for choosing nursing were influenced by the views of parents, the social desire to work in the city, the concerns to provide health care for their families, and the certificates of higher education for a decent job.

Before the one-child generation, the best and most precious opportunities for higher education were usually reserved for boys particularly amongst 
poorer families in rural areas. The participants who entered free nursing education aged 16 to 17 were mainly from families with more than one child with better school performance than their peers. This age group of nurses constitute the main nursing workforce in China (Table 2).

With dramatic demographic changes due to the one-child policy and an unbalanced economic development between the rural and urban area in China, nursing has been regarded as a job for people who are from rural areas or low social class.

It is true that very few city residents would send their children to nursing school; however, in the rural areas, the students... and their parents... their biggest dream is to work in the cities. ... So don't worry. There are still so many people available. (Ling)

Ling's view echoes the popular view hold in Chinese society. Yan was the only participant who said she chose nursing by herself although she has sufficient financial support without having to worry about health care with the urban residential status.

My dad is a doctor. He wants me to learn medicine. My mum wanted me to study in my hometown. ...I considered that nursing would be relatively easier than medicine. I also had a desire to go abroad. (...) Many people said that there was a shortage of nurses in other countries, so it would be easy to work abroad as a nurse. (...) My dad was against my decision for nursing studies. He said: "What good is it to be a nurse? Nurses are shouted at by doctors the whole day." So it was my own idea to choose nursing. (Yan)

As the only child in their family, Yan regarded choosing nursing as a chance to be free from her parents' control by working abroad.

The participants mentioned that they were frequently consulted by their friends, relatives and neighbours for their views on choosing nursing. The majority of respondents commented that young people should be fully informed about the nature of the hard work of nursing and make a free decision based on their personal choice.

\section{Restricting Realistic Expectations of Nursing in Education}

In recent years, Chinese higher educational institutions were encouraged by the government to receive tuition fees from the students instead of offering free education. There are five classes of nursing enrolment according to the national entry examination results. First, $2^{\text {nd }}$ and $3^{\text {rd }}$ class students enter bachelors' degree education, with $3^{\text {rd }}$ class students paying extra tuition fees. Fourth and $5^{\text {th }}$ class students enter associate degree education. Nursing diploma education is still provided for students aged 16 to 17, who are less academically qualified or their family cannot financially support them for their higher education. While the education market became fiercely competitive for 
their institutional survival, several strategies were adopted to attract more students into different levels of nursing studies.

Firstly, the reality of being a nurse in clinical care was deliberately blurred in the nursing recruitment process, especially for nursing at $1^{\text {st }}$ and $2^{\text {nd }}$ class bachelor's degree programme.

The benefits written in the recruitment document were pretty good. It talks about nursing research, nursing education, and nursing management, but it didn't say that you would work as a clinical nurse. (Rao)

It seems that the different images of nursing, which were created in the enrolment phase, were not subsequently clarified during their theoretical nursing education. Yuan described how her classmates' attitudes to nursing changed during their pre-registration nursing studies in the medical universities.

In the first two years, nursing students and medical students took the same courses and examinations together. Our classmates studied hard and we had a very good academic atmosphere. Our average examination results were much higher than those of medical students. (...) Then we were separated in the clinical learning stage. For each disease, usually the doctors gave the lectures first and then the head nurses introduced the nursing strategies of the diseases at the end. I found that nursing was not difficult and we could learn by ourselves. (...) At that time the senior students came back from their work placement and we realized that we still would become clinical nurses under the orders of doctors. One of the senior students went for a Master's degree in medicine, which gave us hope of leaving nursing, so the majority of our classmates began to prepare for the medical postgraduate entrance examinations. (...) There were 30 classmates in my class, only 5 to 6 of them are still working as nurses, 10 of them became doctors, and the others became nursing teachers. One of the classmates graduated with her master's degree in medicine and went back to work in nursing, but she soon left and worked abroad. (Yuan)

The $1^{\text {st }}$ class nursing students were regarded as the best qualified nursing graduates in China. Nevertheless, it seems that nursing education following the medical science orientation and led nursing students to undervalue nursing. Their sound medical foundation seemed to increase the possibility that they went on to postgraduate study in medicine, work abroad or other careers outside of nursing.

Secondly, while recruitment to nursing education programmes in top universities currently faces great challenges, involuntarily transferring students into nursing studies from other subjects has been another means to increase 
numbers. However, a lack of proper support for students who involuntarily entered nursing has a negative impact on students' learning.

Meanwhile, the ideal of working abroad as a nurse was encouraged in Chinese nursing education. This global market strategy has resulted in the educational institutions increasing their investment to focus on increasing Chinese nurses' English capability for nursing emigration.

By encouraging the possibility of working abroad, many students were attracted into nursing studies by the schools. Learning English became the important task during nursing studies, although it is not enough for graduates to be qualified for working abroad. However, the cost of training for working abroad is too expensive for Chinese nurses, since most of them are from relatively poor families. (Rao)

However, in contrast to the difficulties top universities having to face during the recruitment of nursing student, a low employment rate in the nursing diploma education and nursing associate degrees was presented as a challenge to their educational institutions.

Now the school claims that they will take employment as the priority orientation. Teachers are very worried about it since the rate of employment needs to be met. Some students were arranged to sign fake contracts with some company in the labour market. I would say what a waste! (Xia)

It is difficult for these diploma level educated nurses to find a permanent job in the city as they expected. Xia confirmed that fake contracts have been collaboratively arranged by some educational institutions with intermediary labour companies to reduce the rate of unemployment of nursing graduates. Meanwhile, as a way of seeking work opportunities in the city, re-entering nursing colleges for a higher nursing degree became an attractive choice for some students with a nursing diploma. Thus the actual employment of nurses might be overestimated by official statistics provided by the educational institution and government.

Choosing the Ideal Workplace

Participants regarded the Grade three hospitals as the ideal workplace.

I looked for the big hospitals. The biggest hospitals are the Grade three hospitals... Working in the Grade three hospitals means that, the income, working environment and different aspects of development would be better. (Ming)

The opportunity to work in the Grade three hospitals for new graduates means a stable job with a decent income, combined with better opportunities for personal and career development. Grade three hospitals take a large 
recruitment pool for granted and set up stringent recruitment criteria. Chinese nursing students will often send many applications to different Grade three hospitals in order to increase the chance of working in their ideal workplace.

As a male nurse, Ming commented on the job interview that selection was subject to appearance and gender discrimination.

It is a shame to say, but it is true that your height and appearance are very important.... You know, we just stand and nobody asks you to sit down. We were chosen by them without respect... such kind of feeling is bad. The president of the hospital refused to employ any male nurse in the end. (Ming)

$\mathrm{Li}$ also expressed her frustration when she and six new colleagues were regarded as a good image for the hospital for their appearance and allocated at the out-patient department in their first year practice. Appearance discrimination not only undervalues new nurses' enthusiasm for nursing but also undermined their professional value and identity.

Moreover, the hospital did not provide equal work conditions for all recruits.

In the year we graduated, the hospital employed about 100 new nurses. Only a few nurses employed with dingbian; most of us did not... About 20 were permanent contracted nurses whose treatment was almost the same as our temporary contracted nurses, but they have health care insurance although it is lower than those within dingbian. (...) I did not have the insurance for health care, pension and seasonal bonus like the permanent staff. I feel that is really unfair. You know I did the entire job the same as the others. At that time my salary was only half salary and one third of the monthly bonus of the new nurses within dingbian. ( $\mathrm{Li}$ )

Some nurses did not have equal pay and benefits for doing the same job as the permanent staff within dingbian and subsequently did not feel a sense of belonging. The high rate of leaving among nurses on temporary contracts has been widely reported in Chinese nursing literature (Shang et al. 2014).

\section{Committing to the Organization}

All participants appreciate the chance of working in the Grade three hospitals and try to do a good job at the beginning of their career.

When I started to work in the hospital, I never thought that I would leave the hospital. As it was not easy to get the job in the hospital (...) I was determined to do the job well with all my heart until retirement. (Xиe) 
The majority of participants were bright students, they were highly motivated to study and very soon became the key staff or team leaders in their hospitals. It seems that many participants had a sense of strong organizational commitment although they still lack nursing commitment.

Most participants said that the benefits of working in the hospital limited their intention of leaving nursing. When the participants encounter difficulties, they believed they could pass the difficulties through their efforts, which helped them to be tolerant and manage to stay in nursing. After leaving nursing, Ming actively kept certain privileges of working in the hospital by establishing social connections with his previous colleagues.

The hospital is a huge organization with 1200 staff. Although I left the hospital, I still have regularly contacted many friends in the hospital. We have very close relationship and play together. I ask for help and support whenever I have any personal or work problems and I also help them when necessary. (Ming)

Nurses who are working in the Grade three hospitals became "precious resources" for their family, relatives and friends, since nurses can help them to get safer, easier, cheaper and more effective health care services or even take advantage of the health insurance, which the public might not be aware of or understand.

\section{Struggling with a Professional Identity}

As Chinese hospitals strictly limited the number of nursing staff, nurses often had to work beyond their hours. The well-educated and qualified nurses in the Grade three hospitals struggled with their professional identity since they could not achieve their individual expectations of nursing without an effective skill-mix and team work although they had the knowledge and skills to do so. This often led to fatigue and work stress and less time for personal and family life. Work related stress was mentioned by participants in relation to suicide, depression, fatigue, sleep disorder, nervousness, anxieties and sadness.

\section{...Staying in such a condition for a long time is not healthy. You} have no other choice but to quit. (Yang)

It was not surprising that the evidence shows that losing confidence in the safety and quality of health care within grade three hospital work environment has pushed nurses into leaving nursing practice, which has been reported by us elsewhere (Zhu et al. 2014).

\section{Discussion}

The evidence indicates that although nursing is not a popular career choice in Chinese society, it appears that universities currently have no problem in 
attracting students by adopting different strategies. However, the retrospective experiences of the participants illustrate that the mismatched individual and organizational expectations of nursing has created, while the educational institutions mainly emphasis on attracting more students for their institutional survive, and the hospital organizations emphasis on controlling nursing staffing for saving budge under a market orientation. These mismatched expectations has become a barrier for keeping a sustainable nursing workforce in a long term.

The findings in our study suggested that the interpretation of the current increasing statistical number should be viewed with caution, because not only did some nursing students with a higher level of education simply leave clinical care for other careers, some students with a lower level of education also delayed joining the real nursing workforce.

The study supports the argument that the reasons why nurses entered nursing should be considered in association with the reasons why they leave nursing (Duffield et al. 2004). It should be noted that there is a lack of career education for the students before they enter the higher education in China, and many students were reallocated to nursing from other subjects by universities within Chinese current education system. Therefore it was not surprising that nearly all leavers said that they did not have a clear idea of nursing before they entered nursing. The main reason that participants chose nursing was to meet collective expectations, which were influenced by the views of parents and relatives, the concerns of the health care for their family, for a decent job via the higher education, and for social mobility by working in the city. Due to the inequality of economic, educational and health care provision between the urban and rural areas in China, nursing mainly attracts young women from relatively poor rural backgrounds.

Chinese nurses rarely talked about their initial choice of nursing as the desire to "care for" or "help" others, which has been widely regarded as the accepted attitude to nursing in nursing literature (Brodie et al. 2004, Mills and Blaesing 2000). Many western nursing students enter nursing education for reasons related to personal interest or because of a caring intuition (Brodie et al. 2004, Mackay and Elliott 2002). The evidence suggests that the current demographic, financial, and social changes predict a declining eligible number of nursing applications in China given the one-child generation who were born after 1978 now becoming the core of the Chinese workforce (Greenhalgh 2008).

The high rate of nursing students' attrition in Western countries has caused great educational and financial resources wastage (Brewer and Kovner 2001). Many researchers focus on nursing wastage from the perspective of nursing educators, and the unexpected high academic requirement was identified as the main reason for nursing students' attrition (Brodie et al. 2004, Kotecha 2002, Lavoie-Tremblay et al. 2008, Pellico et al. 2009, Rodgers et al. 2013). Therefore, these studies are mainly concerned with avoiding students leaving their pre-registration education by providing support in the educational settings. However, in our study the majority of leavers were the brightest 
students who worked in their ideal workplaces. It might be too easy to blame nurses for their educational preparation without an understanding of the political climate value of nursing within the organizational expectations. In fact, compared with a relatively high rate of nursing students' attrition in most developed countries (Duffield and O'Brien-Pallas 2002), Chinese nursing students rarely give up their studies because of academic demands in the current education system and the highly competitive employment market.

Duffield et al. (2004) studied inactive nurses in Australia, and reported that nurses who were well qualified and skilled were capable of making the transition to a range of other careers when they decided to leave nursing. Chinese leavers' seem to have similar experiences. While it may be possible to attract more students into nursing to ensure the survival of the educational intuitions, it would inevitably increase students' unrealistic expectations of nursing when nurses were inspired to choose nursing as a stepping stone for other careers rather than actively staying in a nursing career.

The highly competitive selectivity in the ideal workplace implicitly forces the well-educated nurses to accept organizational identity rather than professional identity. However organizational commitment was not always associated with a high level of satisfaction, which concurs with previous literature (Lu et al. 2007, Wagner 2007). Nearly all participants confirmed that understaffing and a high workload forced nurses to do extra work hours and sacrifice their off duty time without extra reward. Nurses concentrated on getting the work done by following organizational rules and procedures, resulting in well-educated nurses struggling with their professional identity as part of mismatched expectations of nursing between the individuals and the hospitals.

Without an effective employment policy to support team work, role insufficiency and role ambiguity occur since nurses expected to care for patients with a humanistic orientation, but are instead required to focus on tasks, which has a negative impact on the morale of the nursing workforce. The majority of participants expressed an unresolved dilemma when they could not meet the expectations of both hospital and patients as a clinical nurse.

\section{Conclusions}

By examining the leavers' educational and employment experiences, the present study shows that the current Chinese nursing educational strategies have not helped nursing students to establish realistic expectations of nursing. When the individual and organizational expectations of nursing are highly mismatched, there may be a risk that highly educated nurses simply leave nursing practice. The education providers and hospital managers need to consider how to cooperate and reduce the mismatched expectations of nursing between individuals and organizations by employing mix-skilled teams to achieve a cost efficient as well as effective health care, which will improve a safer environment thus avoiding a more serious risk of nursing shortages. 


\section{References}

Aiken LH, Cheung R (2008) Nursing Workforce Challenges in the United Sates: Implications for Policy. Health Working Paper No. 35. Available from: http://www.oecd.org/health/health-systems/41431864.pdf.

Anand S, Fan VY, Zhang JH, Zhang LL, Ke Y, Dong Z, Chen LC (2008) China's human resources for health: equality, quality and distribution. The Lancet 372(9651): 1774-1781.

Blumenthal D, Hsiao W (2005) Privatization and its discontents-the evolving Chinese health care system. The New England Journal of Medicine 353(11): 1533-4406.

Blumer H (1969) Symbolic Interactionism: Perspective and Method. NJ: Prentice-Hall Englewood Cliffs.

Brewer C, Kovner CT (2001) Is there another nursing shortage? What the data tell us. Nursing Outlook 49(1): 20-26.

Brodie DA, Andrews GJ, Andrews JP, Thomas GB, Wong J, Rixon L (2004) Perceptions of nursing: confirmation, change and the student experiences. International Journal of Nursing Studies 41: 721-733.

Conway PH, Konetzka RT, Zhu JS, Volpp KG, Sochalski J (2008) Nursing staffing ratios: trends and policy implications for hospitals and the safety net. Journal of Hospitals Medicine 3(3): 193-199.

Dovlo D (2005) Wastage in the health workforce: some perspectives from African countries. Human Resources for Health 3(6). Available from: http://www.humanresourceshealth.com/content /3/1/6.

Duffield C, O'Brien-Pallas L (2002) The nursing workforce in Canada and Australia: two sides of the same coin. Australian Health Review 25(2): 136-144.

Duffield C, Aitken L, O'Brien-Pallas L, Wise WJ (2004) Nursing: a stepping stone to future careers. Journal of Nursing Administration 34(5) 238-245.

Fang Z (2007) Potential of China in global nurse migration. Health Services Research 42(3): 1419-1428.

Gill R (2011) Nursing shortage in India with special reference to international migration of nurses. Social Medicine 6(1): 52-59.

Glaser B, Strauss A (1967) The Discovery of Grounded Theory: Strategies for Qualitative Research. New York: Aldine.

Greenhalgh S (2008) Just One Child: Science and Policy in Deng's China. Berkeley: University of California Press.

Hayes LJ, O'Brien-Pallas L, Duffield C, Shamian J, Buchan J, Hughes F, Lashinger HKS, North N, Stone PW (2006) Nurse turnover: a literature review. International Journal of Nursing Studies 43: 237-263.

Hsiao W (2008) When incentives and professionalism collide. Health Affairs 27(4): 949-951.

ICN-International Council of Nursing (2013) ICN Asia Nursing Workforce Forum. Nursing Workforce Profile Database Summary. Available from: http://www.icn.ch/ images/stories/documents/pillars/sew/DATASHEET_ALL_COUNTRIES_AWFF_ 2013.pdf.

Kotecha M (2002) Exploring nurse leaner wastage/persistence using a discursive approach: towards a theoretical understanding of the subject. Journal of Advanced Nursing 40(2): 210-217.

Lavoie-Trembley M, O'Brien-Pallas L, Gélinas C, Desforges N, Marchionni C (2008) Addressing the turnover issues among new nurses from a generational viewpoint. Journal of Nursing Management 16: 724-733. 
Liang LQ, Zhao HF, Qi JW (2007) Personnel post allocation analysis of general hospitals in Zhejiang Province. Chinese Hospitals 11(3): 17-19 (in Chinese).

Lu H, While AE, Barriball KL (2007) A model of job satisfaction of nurses: a reflection of nurses' working lives in Mainland China. Journal of Advanced Nursing 58(5): 468-479.

Ma J, Lu M, Quan H (2008) From a national, centrally planned health system to a system based on the Market: Lessons from China. Health Affairs 27(4): 937-948.

Mackay L, Elliott J (2002) Nursing recruitment: school daze. Health Service Journal 112(5801): 30-31.

MHPRC (1978) The Protocol of Hospital Human Resources Management Framework. Ministry of Health of PRC. No. 1689, Beijing.

MHPRC (2005) Chinese Nursing Development Project 2005-2010. Ministry of Health of PRC. No. 294, Beijing.

MHPRC (2011) Chinese Nursing Development Project 2011-2015. Ministry of Health of PRC. No. 96, Beijing.

Mills AC, Blaesing SL (2000) A lesson from the last nursing shortage: the influence of work values on career satisfaction with nursing. The Journal of Nursing Administration 30(6): 309-315.

Pellico LH, Brewer C, Kovner CT (2009) What newly licenced registered nurses have to say about their first experiences. Nursing Outlook 57: 194-203.

Rafferty AM, Clarke SP, Coles J, Ball J, James P, McKee M, Aiken LH (2007) Outcomes of variation in hospital nurse staffing in English hospitals: Crosssectional analysis of survey data and discharge records. International Journal of Nursing Studies 44(2): 175-182.

Rodgers S, Stenhouse R, McCreaddie M, Small P (2013) Recruitment, selection and retention of nursing and midwifery students in Scottish universities. Nurse Education Today 33(11): 1301-1310.

Shang LL, You LM, Ma CJ, Altares D, Sloane DM, Aiken L (2014) Nurse employment contracts in Chinese hospitals: impact of inequitable benefit structures on nurse and patient satisfaction. Human Resources for Health. 12(1). Available from: http://www.human-resources-health. com/content/12/1/1.

Silverman D (2010) Doing Qualitative Research ( $2^{\text {nd }}$ edn). London: SAGE.

Wagner CM (2007) Organizational commitment as a predictor variable in nursing turnover research: literature review. Journal of Advanced Nursing 60(3): 235247.

WHO-World Health Organization (2014) World Health Statistics. Geneva: WHO.

Wu ZG (1997) Hospital management improvement in China. Public Administration and Development 17: 267-275.

$\mathrm{Xu}$ Y (2003) Are Chinese nurses a viable source to relieve the US nurse shortage? Nursing Economics 21(6): 269-274.

Zhu JH (2010) Human resource problems in nursing need high attention. Chinese Nursing Management 10(12): 17-20.

Zhu JH (2012) Towards an Understanding of Nurses Leaving Nursing Practice in China. Unpublished PhD Thesis. University of Edinburgh.

Zhu JH, Rodgers S, Melia KM (2014) The impact of safety and quality of health care on Chinese nursing career decision making. Journal of Nursing Management 22(4): 423-432.

Zhu JH, Rodgers S, Melia KM (2015) A Qualitative exploration of nurses leaving nursing practice in China. Nursing Open 2(1): 3-13. Available from: http://onlinelibrary.wiley.com/doi/10.1002/nop2.11/epdf 